TABLE OF CONTENTS

Table of Contents $\ldots \ldots \ldots \ldots \ldots \ldots \ldots \ldots \ldots \ldots \ldots \ldots \ldots \ldots \ldots \ldots \ldots \ldots \ldots \ldots$

Three Generations Meeting (I.S. Herschberg and H.J. van den Herik) .... 1 A Review of Game-Tree Pruning (T.A. Marsland) .................. 3 An Overview of Machine Learning in Computer Chess (S.S. Skiena) ....... 20 A Data Base on Data Bases (H.J. van den Herik and I.S. Herschberg) .... 29 Notes:

The KPK Endgame: A Unit Correction (A.R.D. van Bergen and T. van der

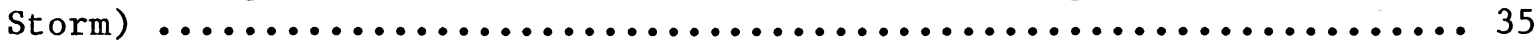

What Constitutes Optimal Play? (R. Seide1) .................. 37 Thompson's New Data-Base Results (I.S. Herschberg and H.J. van den Herik ) .......................................... 45 Reviews :

Turbo Game Works: Tools for Turbo Pascal (T.A. Marsland) ......... 50 News, Information, Tournaments and Reports:

Chess Grandmasters versus Chess Computers (The Editor) ........... 51

The Swedish Rating List (G. Grottling) ..................... 56

The Fifth World Computer-Chess Championship (Cologne) ...........61 The Fifth Conference on Advances in Computer Chess (Noordwijkerhout). 62 Correspondence ..................................... 63

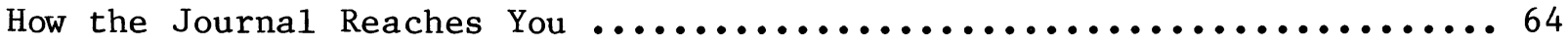

\title{
THREE GENERATIONS MEETING
}

Your Editors feel as happy as the Bach family must have done in 1707 and for precisely the same reason: at least three generations of colleagues met to celebrate a happy occasion. In the eighteenth century, there were three generations of long-lived Bachs assembled to celebrate Johann Sebastian's marriage; posterity may still enjoy part of the proceedings by listening to his unusually light-footed Quodlibet (BWV542). At this early date in 1986 they are the company assembled from three generations of our computer-chess colleagues, uniting forces towards this issue of the Journal.

Many readers may be surprised to find us referring to three generations, they should bear in mind that a computer generation is well below the human span of a quarter-century and is conservatively estimated at some decade or even less: between the birth of silicon and its generative potential, the generation gap is now a handful of years at most and shrinking ....

So do not be surprised, gentle reader, that your Editors regard this issue as a festive meeting of at least three generations of computer-chess practitioners, converging here into a harmonious whole close to our computerchess aims and aspirations. Let us sketch out, however roughly, the three generations which, in meeting, contrive to make this issue a well-blended amalgam of notions.

Some 35 years ago, the idea of search trees was introduced, tentatively and under the tight restriction that this was over three (computer) generations ago and was dastardly hemmed in by the one- or two-Kbit memories then avai1able. Nonetheless, the techniques were developed as far back as the early forties and can be traced back to John von Neumann. This generation of 
computer inventivity is we11 represented, we believe, in Tony Marsland's deliciously long and slightly tutorial article on Game-Tree Pruning.

Your Editors are sure Marsland's contribution presents material for our readers to ponder. Could computers derive the same benefits? The question was first broached some 25 years ago, a generation after the first search trees were grown. It was around 1960 that Samuel seriously applied the concept of computer learning to a game, so successfully that checkers could be said to have been solved for ever after. Learning ideas have modestly permeated computer-chess thinking since and are still with us, as evidenced and even more hinted at in Skiena's contribution to this issue.

While rote learning in simple games (and even checkers is simple in this sense) turned out to be appropriate, it became clear (soon, i.e., a computer generation afterwards) that chess was a different kind of animal altogether. So, in despair at its complexities, the gurus of the Queen of games turned into preachers of the converse:

'granted we can never know a thing about this intractable 32-men game in general, we can at least acquire exhaustive knowledge about four-, five- or even six-men games'.

Thus the gurus created their data bases which they then piously and, for once, correctly, elevated to omniscience.

This line of thought, some 15 years old by now, is also well-represented in this issue, brilliantly and as challengingly as possible by Kenneth Thompson's new results which we regret to have to report at second hand, though we hope to have the privilege of publishing the master's own words in the very near future.

In all, then, this issue comprises three generations' worth of established thought, duly developed into computer-chess ideas. Lest the subject appear trite, the issue also contains a note by one of those quiet revolutionaries which are justly reputed to further the development of science. In this issue, Rainer Seidel challenges, acutely, perceptively and not without humour, our community's current thinking about the very notion of optimality in chess. He seeks to question or even to undermine most of our accepted notions. In doing so, he is in unexpected agreement with Ken Thompson: they concur that computer chess may have a great deal to say about instrumentality (the 'how'), but may have precious little to contribute towards its explicability (the 'why').

Bob Herschberg

Jaap van den Herik

Please note that as of 1986, the ICCA Journal has obtained an International Standard Serial Number (ISSN), which may facilitate retrieval for those in search of references to it. 